\title{
A COMPARISON BETWEEN THE OXIDATION OF BULK LEAD AND THAT OF LEAD DEPOSITS ON Au(111): AN AUGER STUDY
}

\author{
F. PEETERS and A.J. SLAVIN \\ Department of Physics, Trent University, Peterborough, Ontario, Canada K9J $7 B 8$
}

Received 9 August 1988; accepted for publication 2 December 1988

\begin{abstract}
A comparison of the oxidation of bulk lead with the oxidation of thin lead layers on an inert gold substrate provides important information on both processes, particularly on the transition from surface to bulk oxidation. The exposure to oxygen of bulk polycrystalline lead at room temperature rapidly produces an oxide layer which grows laterally as a film $2.0 \pm 0.2$ monolayers thick, followed by much slower oxygen uptake. The same oxide, $\mathrm{PbO}$, forms for lead films of submonolayer to several monolayers thickness, deposited on a Au(111) surface. For lead deposits of less than one monolayer, the oxide grows with a thickness of one monolayer.

Computer decomposition of the lead signal into metal and oxide components has been carried out using the Auger lineshapes for unoxidized metal and thick oxide as basis functions. This method provides chemical information similar to that obtained from X-ray photoelectron spectroscopy.
\end{abstract}

\section{Introduction}

Thin metal films on metal substrates have been studied extensively [1]. Their chemical behaviour is of technological importance to the fields of corrosion science and bimetallic catalysis. In particular, numerous studies have been carried out on the oxidation of lead films deposited onto the noble metals [2-7]. Lead films on $\mathrm{Cu}$ and $\mathrm{Ag}$ were reported to oxidize to orthorhombic $\mathrm{PbO}$ for $\mathrm{Pb}$ coverages from submonolayer to several monolayer $(\mathrm{ML})$ thickness [2-6].

Only one study has investigated the oxidation behaviour of lead films on a $\mathrm{Au}$ substrate [7]. Based on the low ratio of the oxygen to lead-oxide Auger signals, MacMillan-Jones et al. postulated that lead films, deposited onto a polycrystalline Au surface of predominantly (111) orientation, oxidize to lead clusters of about 4 to $5 \mathrm{~Pb}$ atoms per oxygen atom. This behaviour is surprisingly different from that using other noble metals as substrates. It was suggested that the presence of grain boundaries and residual oxygen in the experiments of MacMillan-Jones et al. may have affected the behaviour of the lead films. The present study has, therefore, eliminated grain boundary effects by using a single crystal $\mathrm{Au}(111)$ surface as substrate, and removed all residual 
oxygen by ion bombardment and annealing prior to deposition of $\mathrm{Pb}$. It confirms most of the experimental results of MacMillan-Jones et al., but modifies their interpretation.

Separation of the metallic lead and lead-oxide components of the Auger signal has been accomplished using reference lineshapes obtained in a study of the oxidation of polycrystalline bulk lead. The oxidation of polycrystalline and single crystal lead had been investigated earlier by several techniques [8-13]. Most authors agree that bulk lead oxidizes to orthorhombic PbO. In particular, low energy electron diffraction (LEED) studies by Joyner et al. [12] suggest that even for exposures as low as $100 \mathrm{~L}\left(1 \mathrm{~L}=1\right.$ Langmuir unit $=10^{-6}$ Torr $\cdot s$ ) orthorhombic $\mathrm{PbO}$ is formed.

In all investigations of the oxidation of bulk $\mathrm{Pb}$ the rate of oxidation appears to be greatly reduced once a certain oxide thickness has been reached. For polycrystalline $\mathrm{Pb}$ the oxygen exposure required for this is reported to be $800 \mathrm{~L}$ [8], $1300 \mathrm{~L}$ [9], $3400 \mathrm{~L}$ [10] and approximately $2000 \mathrm{~L}$ [11]. The oxide thickness at the "kneepoint" in the plot of oxygen or lead oxide versus exposure was calculated to be, variously, $1 \mathrm{ML}$ [9] (ref. [12] for 100, 110 surfaces), 2 to $3 \mathrm{ML}$ [8], and $6.3 \AA$ or $2 \mathrm{ML}$ [11].

To our knowledge only one previous Auger electron spectroscopy (AES) study on the oxidation of bulk $\mathrm{Pb}$ has been carried out [11]; it reports only spectra for the oxygen peak at $518 \mathrm{eV}$. Our decomposition of lead/lead-oxide Auger spectra into the $\mathrm{Pb}(94 \mathrm{eV})$ and $\mathrm{PbO}(91 \mathrm{eV})$ components enables a comparison of $\mathrm{Pb}, \mathrm{PbO}$ and oxygen peaks for different lead oxide thicknesses (henceforth, the "PbO peak" refers to the oxide component of the lead Auger signal near $94 \mathrm{eV}$ ). The AES study of the oxidation of bulk lead not only provides reference Auger lineshapes for the Au(111) work, but also, by comparison with the $\mathrm{Pb}$ film work, provides information on the oxidation of bulk lead.

This study also shows that the decomposition of Auger spectra can provide chemical information similar to that obtained from XPS (X-ray photoelectron spectroscopy), given that the basis functions for the decomposition are available.

\section{Experimental}

The apparatus was the same as that used by MacMillan-Jones et al. [7] with the addition of an argon ion gun for sample cleaning. Auger spectra were recorded by a microcomputer interfaced with a 4-grid LEED-type analyzer operated in the derivative mode. The modulation voltage was $2 \mathrm{~V}$ peak-to-peak for the $\mathrm{Pb}$ and $\mathrm{Au}$ peaks and $11 \mathrm{~V}$ peak-to-peak for oxygen. All spectra were taken at a primary energy of $1500 \mathrm{eV}$ and a beam current of $15 \mu \mathrm{A}$. Reported peak positions always refer to the minima in the $\mathrm{d} N(E) / \mathrm{d} E$ spectra. The 
polycrystalline $\mathrm{Pb}$ and a sparkcut and mechanically polished $\mathrm{Au}(111)$ sample were cleaned by argon ion bombardment at $500 \mathrm{~K}(\mathrm{~Pb})$ and $900 \mathrm{~K}(\mathrm{Au})$. After annealing for 5 min the Auger signals of contaminants typical for $\mathrm{Au}$ and $\mathrm{Pb}$ $(\mathrm{C}, \mathrm{Ca}, \mathrm{Cl}, \mathrm{O})$ were below the detection limit of our apparatus, with the exception, for the lead sample, of a small oxygen signal typically $3 \%$ of that measured for the maximum $\mathrm{O}_{2}$ exposure of $3 \times 10^{9} \mathrm{~L}$. Lead films on $\mathrm{Au}(111)$ were prepared by evaporation of lead previously deposited on a platinum ribbon [7]. All experiments were carried out at room temperature and background pressures of typically $2 \times 10^{-9}$ Torr. During oxygen exposures $\mathrm{O}_{2}$ was admitted into the chamber at pressures between $1 \times 10^{-7}$ and 0.1 Torr as measured by a Bayard-Alpert gauge (BAG) and a Hastings gauge. All pressures and exposures are given as uncorrected $\mathrm{BAG}$ and Hastings gauge measurements as is common practice. The true $\mathrm{O}_{2}$ pressure readings for exposures of less than $10^{4} \mathrm{~L}$ can be obtained by multiplying the uncorrected values by $2.76 \pm 0.7 \%$, determined by calibration against a Baratron capacitance manometer.

\section{Results}

\subsection{Bulk lead}

A typical sequence of lead/lead-oxide lineshapes found for different $\mathrm{O}_{2}$ exposures of bulk lead is given in fig. 1. The spectra of clean bulk $\mathrm{Pb}$, and of $\mathrm{Pb}$ exposed to $3 \times 10^{9} \mathrm{~L}$ of $\mathrm{O}_{2}$ (figs. $1 \mathrm{a}$ and $1 \mathrm{e}$ ), were used as basis functions for the decomposition of the lead/lead-oxide lineshapes. Components obtained by allowing the two basis functions to vary in height and position independently produced reconstructed curves which showed excellent agreement with the original data (fig. 2). This decomposition procedure assumes that the $\mathrm{PbO}$ lineshape is independent of the exposure to $\mathrm{O}_{2}$. Support for this assumption is obtained from the results on oxidation of lead films on a gold substrate discussed below.

Further evidence for the validity of the fitting procedure is obtained as follows. Assuming that the inelastic mean free paths (IMFP's) of the $94 \mathrm{eV}$ electrons from $\mathrm{Pb}$ travelling through $\mathrm{PbO}\left(\lambda_{94}\right)$ and for the $91 \mathrm{eV}$ electrons from $\mathrm{PbO}$ travelling through $\mathrm{PbO}\left(\lambda_{91}\right)$ are the same, the sum of the properly normalized coefficients for the $\mathrm{Pb}$ and $\mathrm{PbO}$ components is expected theoretically to be unity. This can be shown by the calculation of the signal from a $\mathrm{PbO}$ layer of thickness $d\left(\mathrm{PbO}_{d}\right)$ normalized to that of bulk $\mathrm{PbO}\left(\mathrm{PbO}_{\text {bulk }}\right)$, and the signal from bulk $\mathrm{Pb}$ below a $\mathrm{PbO}$ layer of thickness $d\left(\mathrm{~Pb}_{\text {below }}\right)$ normalized to that of clean bulk $\mathrm{Pb}\left(\mathrm{Pb}_{\text {bulk }}\right)$. The constant 0.74 in these equations is a geometrical factor for our analyzer [14]:

$$
\begin{aligned}
& \mathrm{PbO}_{d} / \mathrm{PbO}_{\text {bulk }}=1-\exp \left[-d /\left(0.74 \lambda_{91}\right)\right], \\
& \mathrm{Pb}_{\text {below }} / \mathrm{Pb}_{\text {bulk }}=\exp \left[-d /\left(0.74 \lambda_{94}\right)\right], \\
& \mathrm{PbO}_{d} / \mathrm{PbO}_{\text {bulk }}+\mathrm{Pb}_{\text {below }} / \mathrm{Pb}_{\text {bulk }}=1, \text { if } \lambda_{94}=\lambda_{91} .
\end{aligned}
$$




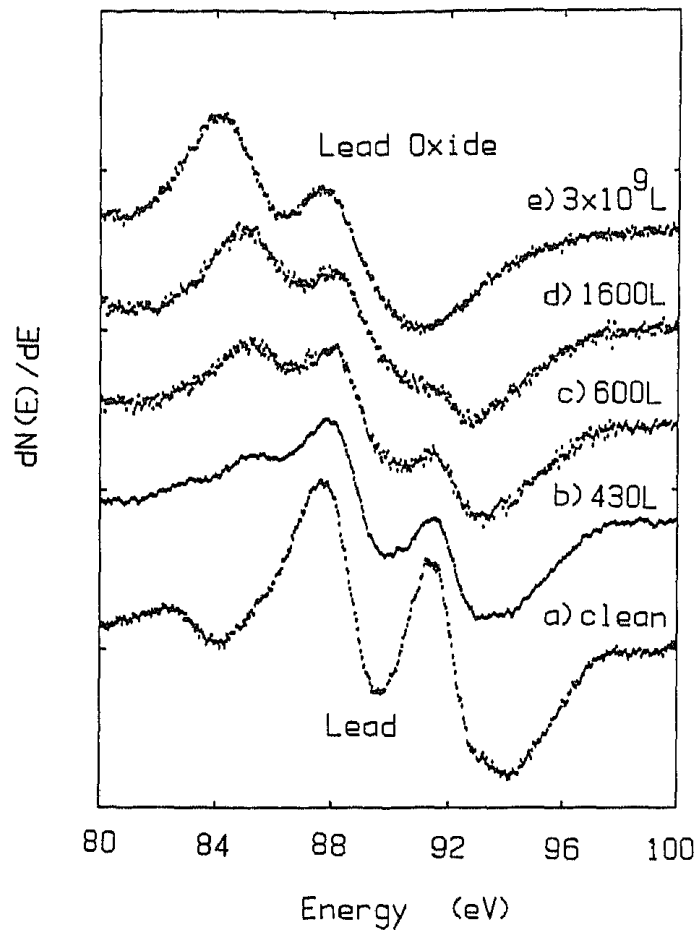

Fig. 1. Auger lineshapes of polycrystalline lead for different $\mathrm{O}_{2}$ exposures: (a) clean lead; (b) 430 $\mathrm{L}$; (c) $600 \mathrm{~L}$; (d) $1600 \mathrm{~L}$; (e) $3 \times 10^{9} \mathrm{~L}$ (lead oxide).

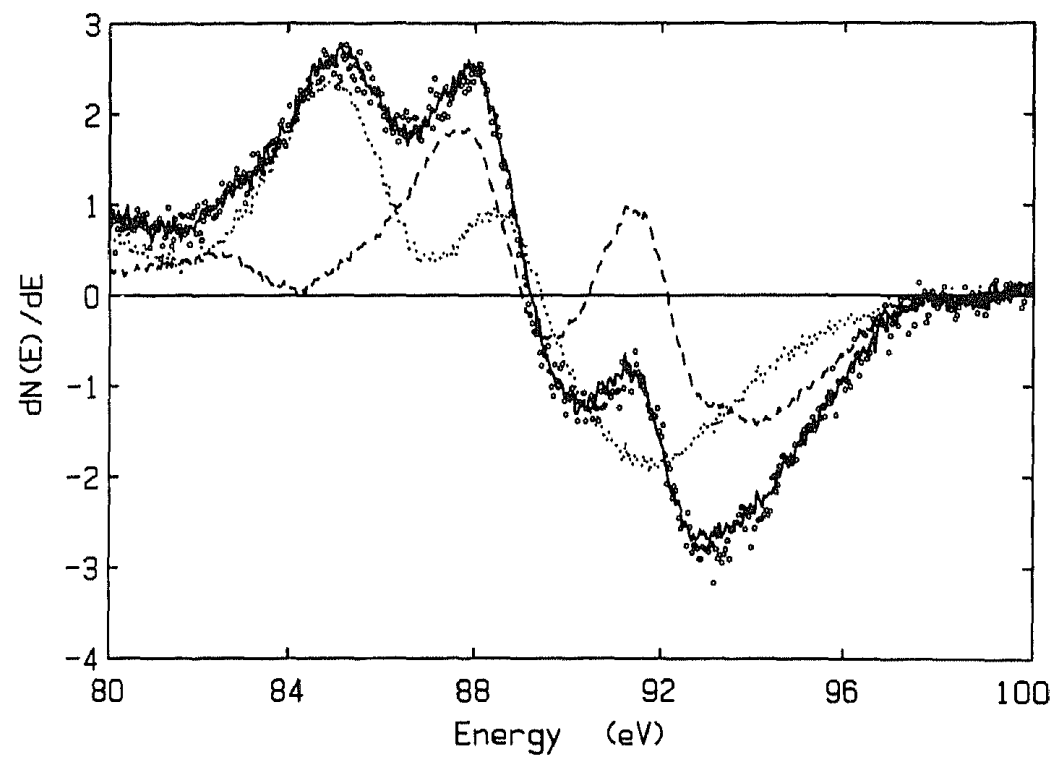

Fig. 2. Decomposition of the lead/lead-oxide lineshape for a $600 \mathrm{~L}$ exposure of polycrystalline lead: $(\bullet)$ original data; ( - ) fitted curve; $(\cdots \cdots)$ PbO component; $\left({ }_{-}\right.$, ) $\mathrm{Pb}$ component. 


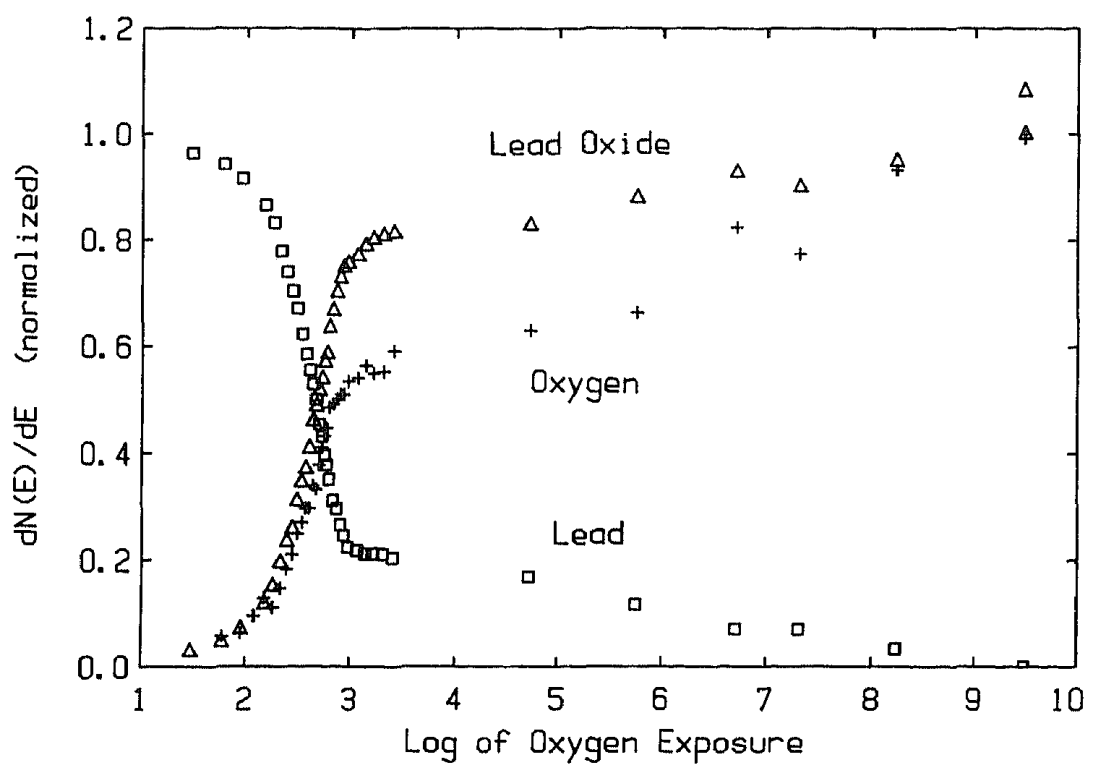

Fig. 3. Development with oxygen exposure of the peak-to-peak heights for the $(\Delta) \mathrm{PbO}$ component; $(+)$ oxygen peak; $(\square) \mathrm{Pb}$ component.

Experimentally this sum was measured to be $0.98 \pm 3 \%$ for any curve decomposed. The low degree of variation and sums of very close to 1 indicate the validity of the fitting procedure.

For $\mathrm{O}_{2}$ doses up to $1000 \mathrm{~L}\left(\mathrm{O}_{2}\right.$ pressure $1 \times 10^{-7}$ Torr $)$ the $\mathrm{PbO}$ and the $\mathrm{O}$ Auger signals increased rapidly, while the $\mathrm{Pb}$ signal decreased (fig. 3), not reaching zero until an exposure near $3 \times 10^{9} \mathrm{~L}$ (at 0.1 Torr). The $\mathrm{Pb}$ signal is normalized to the clean $\mathrm{Pb}$ peak, while the $\mathrm{PbO}$ signal and the oxygen peak are normalized to the $\mathrm{PbO}$ and oxygen peaks after a $3 \times 10^{9} \mathrm{~L} \mathrm{O}_{2}$ exposure. At this exposure the absence of a metallic lead component shows that the lead was fully oxidized within the Auger sampling depth. The corresponding $\mathrm{PbO}$ and O signals will be termed "saturation values". In fact, because of the longer IMFP of the $518 \mathrm{eV}$ electrons, the oxygen signal will be at only about $91 \%$ when the lead-oxide signal has already reached $99 \%$ of its saturation value. By $1300 \mathrm{~L}$ the $\mathrm{PbO}$ had already reached $79 \%$ and the oxygen $55 \%$ of their respective saturation values at $3 \times 10^{9} \mathrm{~L}_{2}$, whereas the $\mathrm{Pb}$ peak had decreased to $21 \%$ of the clean bulk $\mathrm{Pb}$ value. It is difficult to choose a specific oxygen exposure at which the rate of oxygen uptake changes from rapid to slow. Since the plots in fig. 3 are essentially linear above $1300 \mathrm{~L}$ this exposure was chosen as the transition point. No attempt has been made to investigate the pressure dependence of the rate of oxidation above $1300 \mathrm{~L}$. The pressures used were chosen for convenience and ranged from $1 \times 10^{-7}$ to 0.1 Torr.

The oxide peak was shifted to a lower energy relative to the metallic lead peak by about $2.8 \mathrm{eV}$. The $\mathrm{PbO}$ peak continued to shift slightly with increasing 


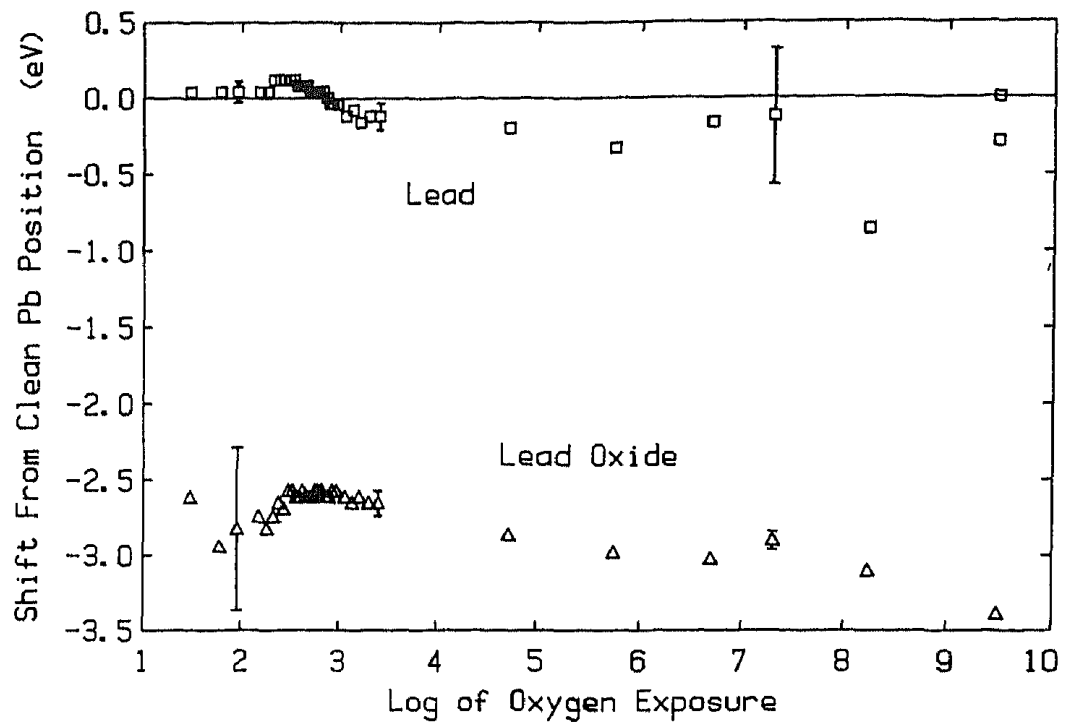

Fig. 4. Shifts of the $\mathrm{Pb}$ and $\mathrm{PbO}$ peaks relative to clean $\mathrm{Pb}$ for different $\mathrm{O}_{2}$ exposures (in Langmuir units) of polycrystalline $\mathrm{Pb}:(\Delta) \mathrm{PbO}$ component; ( $\square$ ) $\mathrm{Pb}$ component.

oxygen exposures (fig. 4). Because of the large uncertainty in the measurement of the metallic lead component at high oxygen exposures, it is unclear whether this peak position remains constant or also shifts slightly. It is not unreasonable that the $\mathrm{PbO}$ peak should continue to shift slowly as the oxide thickens.

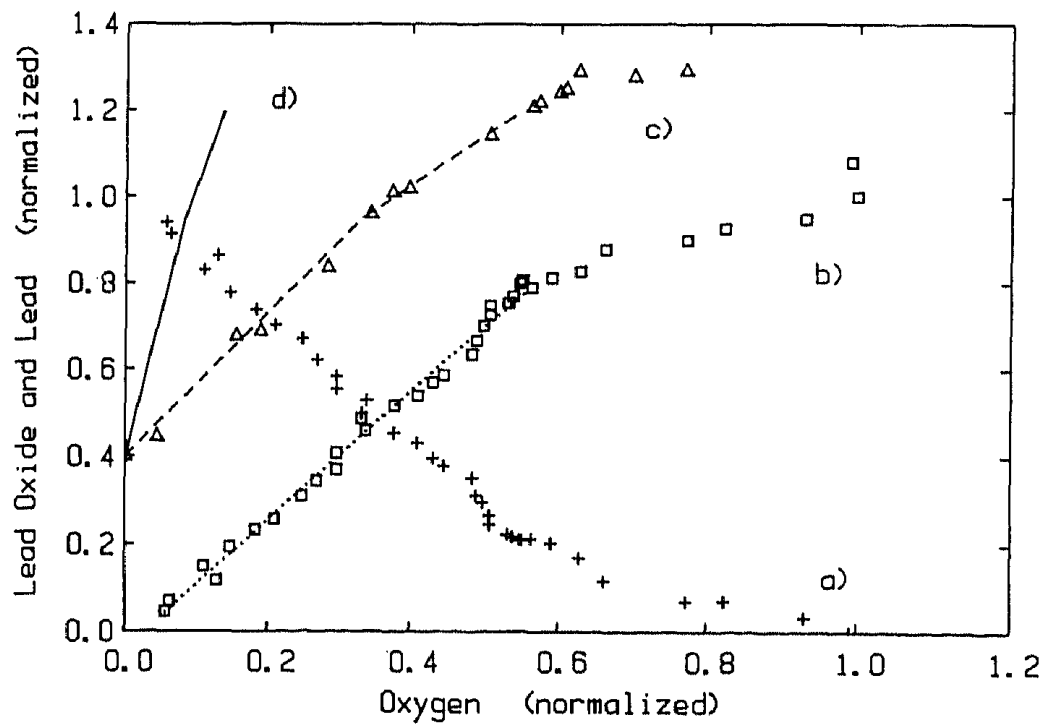

Fig. 5. Relationship between the lead oxide or lead and the oxygen Auger peak heights. (a) $\mathrm{Ph}$ peak for bulk lead: (+) experimental. (b) PbO peak for bulk lead: (ㅁ) experimental; $(\ldots \ldots)$ regression line for data up to $1300 \mathrm{~L}$. (c) PbO peak for lead film on $\mathrm{Au}(111)$ : $(\Delta)$ experimental: (- - ) expected for $\mathrm{PbO}$ with layer-by-layer growth. (d) Lead oxide for lead film on Au(111): (-) expected for $\mathrm{Pb}_{4} \mathrm{O}$ with layer-by-layer growth. Curves (c) and (d) are shifted upwards by $0.4 \mathrm{eV}$ for clarity. 
The size of the uncertainty in the measurements also makes it unclear whether the maxima in shifts near an exposure of some $30 \mathrm{~L}$ are real or not. It was not possible to determine whether a similar shift occurred for the oxygen peak because the larger modulation voltage ( $11 \mathrm{~V}$ peak-to-peak) resulted in too low a resolution at this energy. The total shift from the clean lead peak (at $0 \mathrm{~L}$ ) to fully oxidized $\mathrm{PbO}$ is $3.4 \mathrm{eV}$. This is close to the value of $3.7 \pm 0.2 \mathrm{eV}$ measured for the integrated spectra (these values are not expected to be exactly the same, because the first uses the minimum in the $\mathrm{d} N(E) / \mathrm{d} E$, and the second the maximum in the $N(E)$ spectrum, and the lineshapes are different).

The ratio between $\mathrm{PbO}$, or $\mathrm{Pb}$, and $\mathrm{O}$ Auger signals was found to be constant for normalized lead-oxide peak-to-peak heights of up to $0.80 \pm 0.01$ (fig. 5) obtained for exposures of about $1300 \mathrm{~L}$. The slight offset from the origin for the $\mathrm{PbO} / \mathrm{O}$ data is due to the presence of residual oxygen on the lead, and produces a negligible error. For exposures larger than about $1300 \mathrm{~L}$ the slopes of both plots changed to lower values.

\subsection{Lead films on $A u(I 11)$}

Exposure of the $\mathrm{Au}(111)$ surface to an increasing number of identical $\mathrm{Pb}$ evaporations resulted in $\mathrm{Pb}$ and $\mathrm{Au}$ Auger signals as shown in fig. 6. From the absolute values of the $\mathrm{Pb}$ signal at the first breakpoint in fig. 6 , which is considered to represent a $\mathrm{Pb}$ coverage of 1 monolayer [7,15-17], and the clean bulk $\mathrm{Pb}$ signal of fig. $1 \mathrm{a}$, an IMFP of $94 \mathrm{eV}$ electrons from $\mathrm{Pb}$ through $\mathrm{Pb}$ can

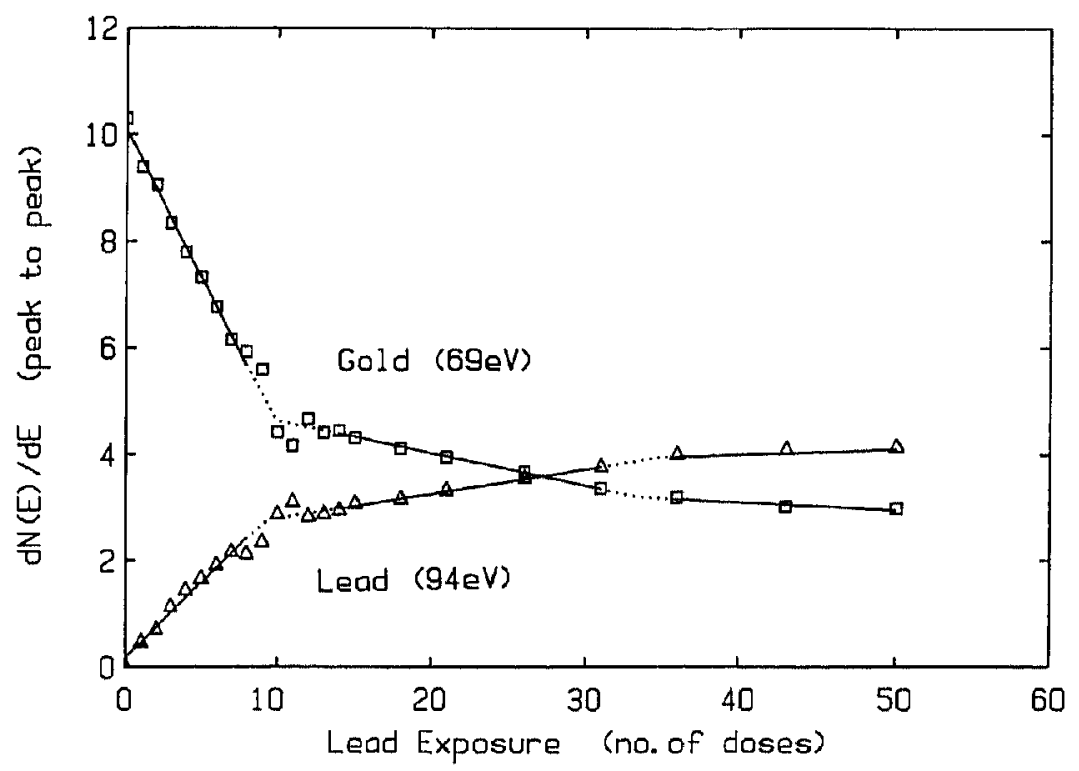

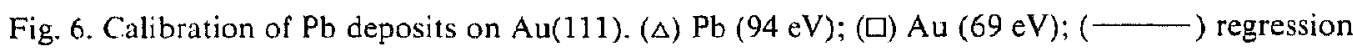
lines; $(\cdots \cdots)$ extrapolation. 
be calculated as in eq. (1) to be $1.7 \pm 0.1 \mathrm{ML}$. The unit of monolayers (ML) for a mean free path will be defined as that thickness of an overlayer causing an attenuation in the Auger signal equal to the attenuation produced by the $\mathrm{Pb}$ film on $\mathrm{Au}(111)$ at the first breakpoint. The calculation above assumes that the $\mathrm{Pb}$ density in the $\mathrm{Pb}$ layer at the breakpoint is the same as the $\mathrm{Pb}$ density in layers of bulk lead, and that backscattering factors are identical for both polycrystalline $\mathrm{Pb}$ and the $1 \mathrm{ML} \mathrm{Pb}$ film on $\mathrm{Au}(111)$. Once the data of fig. 6 was obtained, the amount of any lead deposited on the Au(111) surface could be determined by either the ratio of lead and gold Auger signals, or by the attenuation of the gold Auger signal, using the monolayer breakpoint as reference and assuming constant $\mathrm{Pb}$ sticking probability. The fact that the gold signal never approaches zero in fig. 6 indicates that dosages larger than 1 monolayer equivalent $(\mathrm{ME})$ of $\mathrm{Pb}$ result in the formation of a lead-gold surface alloy, as discussed in earlier studies (ref. [7] and references therein). There is some evidence of a second breakpoint in the curves of fig. 6 for a deposition of 3 ME's of lead, but it is not clear enough to warrant further discussion.

Oxygen exposure of the clean $A u(111)$ surface does not lead to oxygen uptake (ref. [7] and references therein). $\mathrm{Pb}$ films deposited on a $\mathrm{Au}(111)$ surface and then dosed with about $5000 \mathrm{~L}$ of oxygen (or $5 \times 10^{6} \mathrm{~L}$ in the case of $\mathrm{Pb}$ deposits larger than $6 \mathrm{ME}$ ) showed lead-oxide Auger lineshapes essentially identical to the $\mathrm{PbO}$ lineshape shown in fig. 1e. In fact, a decomposition of the lead/lead-oxide Auger peaks of oxidized lead deposits on Au(111) (fig.

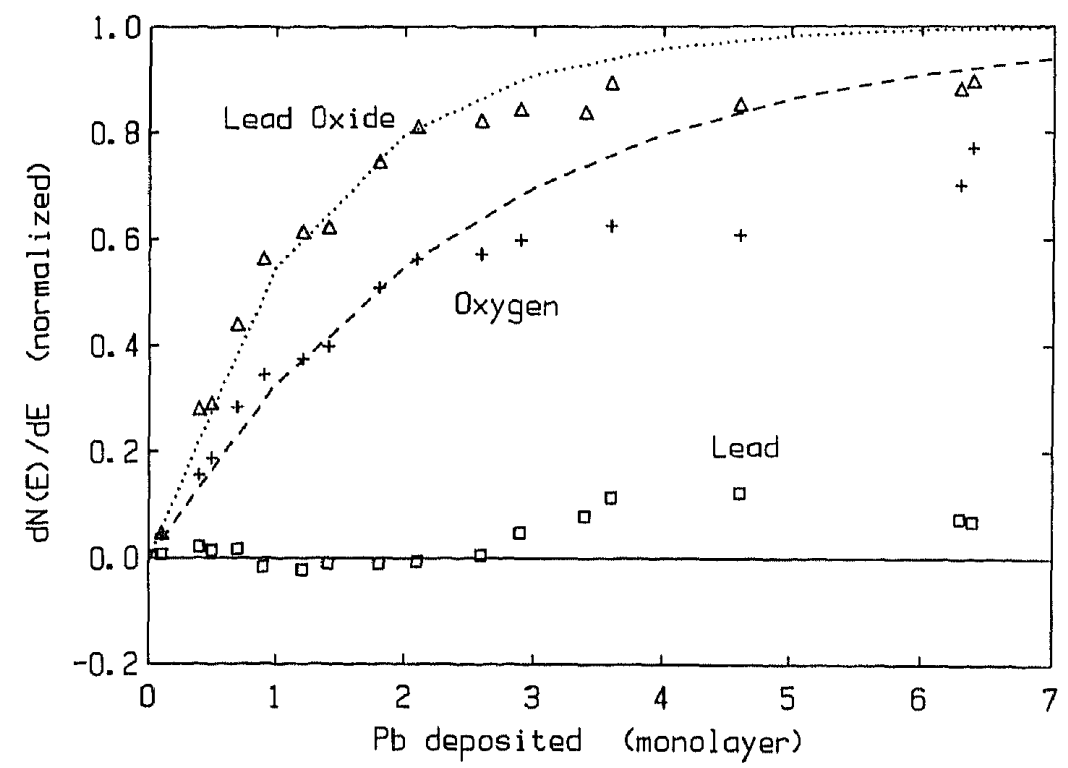

Fig. 7. Auger peak-to-peak heights for different Pb coverages. ( $\Delta$ ) lead-oxide component: ( $\square) \mathrm{Pb}$ component; $(+)$ oxygen peak $(518 \mathrm{eV}) ;(\cdots)$ calculated for layer-by-layer growth using the IMFP's for lead oxide and (_- - for oxygen electrons through $\mathrm{PbO}$. 
7), using the same basis functions as for the decomposition of lineshapes on bulk lead, showed only an oxide component up to 2.5 $\mathrm{ME}$ of $\mathrm{Pb}$. Above this value, the metallic-lead component is also present which indicates that the lead films were not fully oxidized at the oxygen exposures used. Both the oxygen and lead-oxide signals for oxygen-saturated lead films on $\mathrm{Au}(111)$ increased with the lead coverage (fig. 7). The dotted and dashed lines in fig. 7 were calculated with no adjustable parameters, assuming that: (1) the lead oxide grows layer-by-layer and (2) the electron IMFP's in $\mathrm{PbO}$ are the same as in $\mathrm{Pb}$. The second assumption is supported by a comparison of the theoretical IMFP's in $\mathrm{Pb}$ and $\mathrm{PbO}$, using a calculation developed by Penn [19], which shows that at $94 \mathrm{eV}$ the IMFP's differ by less than 3\%. The IMFP used for electrons from oxygen was $\lambda_{518}=3.4 \mathrm{ML}$, which will be calculated later.

The calculated values of the $\mathrm{PbO}$ and $\mathrm{O}$ signal strengths from fig. 7 have been used to plot the dashed line in fig. 5c. It involves no adjustable parameters. Agreement with the experimental data is excellent, including the break in slope at a lead deposit of $1 \mathrm{ME}$, and gives support for layer-by-layer growth of the lead oxide up to at least 2 monolayers. The ratio of the $\mathrm{PbO}$ and $\mathrm{O}$ signals was very similar to that found during oxidation of bulk $\mathrm{Pb}$ (fig. $5 \mathrm{~b}$ ).

For all $\mathrm{Pb}$ coverages the $\mathrm{Au}$ signal from the substrate after oxidation was smaller than the Au signal before oxidation as found previously [7].

LEED showed the expected 6-fold pattern for the clean $\mathrm{Au}(111)$ substrate. The more complex details observed by others [20] could not be resolved, which may be attributed to the limited quality of our analyzer. No clearly defined patterns for the lead films before or after oxidation could be identified although new but faint diffraction spots were observed after $\mathrm{Pb}$ deposition.

\section{Discussion}

\subsection{Bulk lead}

The Auger lineshape for lead oxide in fig. 1e and the separation of $3.7 \pm 0.2$ $\mathrm{eV}$ of the integrated metallic $\mathrm{Pb}$ and the $\mathrm{PbO}$ peaks at $3 \times 10^{9} \mathrm{~L}$ compare well with the lineshape and the shift of $3.8 \mathrm{eV}$ reported for bulk $\mathrm{PbO}$ [18]. This indicates that the oxidation of polycrystalline $\mathrm{Pb}$ leads to the formation of $\mathrm{PbO}$, which is in agreement with earlier studies [8,10-13].

Joyner et al. [12] concluded from LEED experiments on oxidized $\mathrm{Pb}(100)$ and $\mathrm{Pb}(110)$ crystals that orthorhombic $\mathrm{PbO}$ is formed on both substrates even for oxygen exposures as small as $100 \mathrm{~L}$. If the stoichiometry of the lead oxide formed on polycrystalline $\mathrm{Pb}$ is independent of $\mathrm{O}_{2}$ exposure, the $\mathrm{PbO} / \mathrm{O}$ Auger signal ratio is expected to remain constant until a complete layer of lead oxide is formed. Further oxidation should result in a different ratio caused by the different IMFP's for lead and oxygen Auger electrons $\left(\lambda_{518} \approx 2.0 \lambda_{94}\right)$. Fig. 
5 shows that the change in the ratio of the $\mathrm{PbO} / \mathrm{O}$ signals occurs at a normalized $\mathrm{PbO}$ peak-to-peak height of $0.80 \pm 0.01$, which corresponds to an $\mathrm{O}_{2}$ exposure of approximately 1300 L. Just prior to this exposure the $\mathrm{O}_{2}$ sticking probability decreased drastically (fig. 3). These observations indicate that at about $1300 \mathrm{~L}$ a complete $\mathrm{PbO}$ layer is formed, greatly inhibiting further oxidation of the lead underneath. This exposure of $1300 \mathrm{~L}$ agrees reasonably well with the "kneepoint" exposures reported in refs. [8,9,11]. The differences may be due to variations in the calibration of the gauges used, or the difficulty in defining the knee position.

Using the Auger peak heights for clean $\mathrm{Pb}$ and for the metallic lead component at $1300 \mathrm{~L}$ and assuming a homogeneous oxide layer, the thickness of the completed $\mathrm{PbO}$ layer can be calculated using the IMFP, $\lambda_{94}$, to be $2.0 \pm 0.2 \mathrm{ML}$. This lead-oxide thickness is consistent with results obtained by ellipsometry [11], XPS and UPS [8], and is strongly supported by our results found for the oxidation of $\mathrm{Pb}$ films on $\mathrm{Au}(111)$. The $\mathrm{PbO}$ peak-to-peak height from fig. 7 for an $\mathrm{O}_{2}$-saturated lead film of $2.0 \pm 0.2 \mathrm{ME}$ on $\mathrm{Au}(111)$ agrees with the $\mathrm{PbO}$ peak-to-peak height found for the $1300 \mathrm{~L}$ exposure of bulk $\mathrm{Pb}$.

The IMFP for oxygen electrons (518 eV) through $\mathrm{PbO}$ can be obtained from the oxygen peak-to-peak height at the $2 \mathrm{ML}$ completion to be $\lambda_{518}=3.4$ $\mathrm{ML}$ using eq. (1). Since both the $\mathrm{PbO} / \mathrm{O}$ and $\mathrm{Pb} / \mathrm{O}$ slopes remain constant up to the completion of the $2 \mathrm{ML}$ thick $\mathrm{PbO}$ film on bulk lead (fig. 5), with no break in slope as seen for deposits on gold, oxygen exposures from 60 to 1300 $\mathrm{L}$ seem to result in the formation of a $2 \mathrm{ML}$ thick lead oxide. This $\mathrm{Pb}$ appears to grow laterally with increasing $\mathrm{O}_{2}$ exposure, until at about $1300 \mathrm{~L}$ a $2 \mathrm{ML}$ thick $\mathrm{PbO}$ film is completed. This $\mathrm{PbO}$ film hinders further oxygen uptake so effectively that even for an exposure of $2 \times 10^{8} \mathrm{~L}$ the oxide formed can be estimated from the data of fig. 3 to be only $4.5 \mathrm{ML}$ thick.

\subsection{Lead films on $A u(111)$}

In an earlier investigation [7] a comparison of lead-oxide and oxygen Auger peak heights with handbook data led to the suggestion that the oxidation of $\mathrm{Pb}$ films deposited on polycrystalline $\mathrm{Au}$ results in the formation of $\mathrm{Pb}_{4} \mathrm{O}$ or $\mathrm{Pb}_{5} \mathrm{O}$. However, the Auger lineshape in fig. 1e for oxygen-saturated bulk lead is essentially identical to the lineshape for oxygen-saturated lead films on $\mathrm{Au}(111)$ (saturation was obtained for films up to $2.5 \mathrm{ME} \mathrm{Pb}$ ). This suggests that oxygen adsorption either on polycrystalline lead, or on lead films deposited onto a gold substrate, leads to the formation of the same lead-oxide compound, namely $\mathrm{PbO}$. Moreover, for $\mathrm{Pb}_{4} \mathrm{O}$ or $\mathrm{Pb}_{5} \mathrm{O}$ compounds the leadoxide-to-oxygen ratio would be expected ot be 4 to 5 times larger than the ratio found for $\mathrm{PbO}$ on bulk lead, whereas the lead-oxide/oxygen Auger ratios found for lead films deposited onto an $\mathrm{Au}(111)$ substrate and saturated with oxygen compare very well with the ratios found for $\mathrm{PbO}$ on bulk $\mathrm{Pb}$ (fig. 5). 
Most of the data reported by MacMillan-Jones et al. [7] for a predominantly (111) polycrystalline Au substrate appear to be almost identical to the data reported here for the $\mathrm{Au}(111)$ surface. Therefore, the lead oxide formed in both studies appears to be orthorhombic $\mathrm{PbO}$ rather than clusters of $\mathrm{Pb}_{4} \mathrm{O}$ or $\mathrm{Pb}_{5} \mathrm{O}$.

MacMillan-Jones et al. also suggested that for all thin lead films on Au some lead remained unoxidized even for large oxygen exposures, whereas the present results show complete oxidation to $\mathrm{PbO}$ under these conditions up to 2.5 ME. Above $2.5 \mathrm{Me}$ the lead films have not been fully oxidized by exposures about $5000 \mathrm{~L}$, or $10^{6} \mathrm{~L}$ in the case of $6 \mathrm{ML}$ thick deposits. This is not surprising since an exposure of $10^{6} \mathrm{~L}$ was required for bulk lead to reduce the metallic $\mathrm{Pb}$ component to $9 \%$ of its original value, corresponding to an oxide layer $3 \mathrm{ML}$ thick. The error in the earlier work resulted from the use of a single basis function, that of clean lead, in the decomposition of the lead Auger peak. A comparison of the present study with that of MacMillan-Jones et al. thus brings out two important points:

(1) The scaling of amplitudes from Auger handbook data may result in estimates of surface concentrations which are in error by several hundred percent unless the chemical systems compared are very similar.

(2) Reliable basis functions are needed in decomposing overlapping Auger spectra. Good agreement between original data and reconstructed curves does not in itself imply an acceptable decomposition.

The comparison between experiment and theory in fig. 7 for initial $\mathrm{Pb}$ coverages less than $2 \mathrm{ME}$ indicates that it is possible to form a monolayer-thick oxide, although on bulk lead the initial oxide is $2 \mathrm{ML}$ thick. This is further supported by the following argument. For coverages less than $2 \mathrm{ME}$ of $\mathrm{Pb}$, the formation on oxidation of a $2 \mathrm{ML}$ thick $\mathrm{PbO}$ film as on bulk $\mathrm{Pb}$ would require coalescence of the lead on the surface, which should cause an increase in the Au Auger signal. However, in all experiments the Au signal was found to be decreased after oxidation. (For initial coverages greater than $2 \mathrm{ME} \mathrm{Pb}$ the ratio of the Au signal after oxidation to that before oxidation was very small, which can be explained by the migration of $\mathrm{Pb}$ atoms towards the surface of the lead-gold alloy as discussed in detail by MacMillan-Jones et al. [7].)

The discussion in ref. [7] of the reactivity of the $\mathrm{Au} / \mathrm{Pb}$ surface vis-à-vis that on $\mathrm{Cu} / \mathrm{Pb}$ or $\mathrm{Ag} / \mathrm{Pb}$ also appears to remain essentially valid.

\section{Conclusions}

The technique of comparing oxidation of a bulk metal with the oxidation of thin layers of the same metal on an inert substrate can provide important information about both processes. The oxidation of bulk polycrystalline $\mathrm{Pb}$ leads initially to the formation of orthorhombic $\mathrm{PbO}$ which grows laterally as 
a layer $2.0 \pm 0.2 \mathrm{ML}$ thick. At an exposure of about $1300 \mathrm{~L}$ this film is completed, reducing further oxygen uptake dramatically.

The oxidation of thin $\mathrm{Pb}$ films on $\mathrm{Au}(111)$ and polycrystalline $\mathrm{Au}$ also leads to the formation of orthorhombic $\mathrm{PbO}$ for all $\mathrm{Pb}$ coverages, rather than $\mathrm{Pb}_{4} \mathrm{O}$ or $\mathrm{Pb}_{5} \mathrm{O}$ as suggested earlier. Oxidation of $\mathrm{Pb}$ films of less than $2 \mathrm{ME}$ does not result in coalescence of the lead to produce a $2 \mathrm{ML}$ thick oxide layer.

Decomposition of Auger spectra can be used reliably to analyze overlapping Auger spectra provided that all required basis functions are available.

\section{Acknowledgements}

The authors would like to express their thanks to K. Fowler and J.A. Tomlinson for excellent technical support and F.A. Londry for software development. The gold sample was generously provided by Dr. M. Swanson of the University of North Carolina. Financial assistance from the Natural Science and Engineering Research Council of Canada and Trent University has made this work possible.

\section{References}

[1] G.E. Rhead, Contemp. Phys. 24 (1983) 535.

[2] D. Chadwick and M.A. Karolewski, Appl. Surface Sci. 9 (1981) 98.

[3] C. Ocal, E. Martinez and J. Ferrer, Surface Sci. 136 (1983) 571.

[4] D. Chadwick, A.B. Christie and M.A. Karolewski, Vacuum 31 (1981) 705.

[5] D. Chadwick and A.B. Christie, Surface Sci. 82 (1979) L293.

[6] D. Chadwick and M.A. Karolewski, Phys. Scripta T 4 (1983) 103.

[7] J.G. MacMillan-Jones, F.A. Londry and A.J. Slavin, Surface Sci. 186 (1987) 357.

[8] D. Chadwick and A.B. Christie, J. Chem. Soc. Faraday Trans. II, 76 (1980) 276.

[9] S. Evans and J.M. Thomas, J. Chem. Soc. Faraday Trans. II, 71 (1975) 313.

[10] P. Hewitt and N. Winogard, Surface Sci. 78 (1978) 1.

[11] N.J. Chou, J.M. Eldrige, P. Hammer and D.W. Dong, J. Electron, Mater. 2 (1973) 115.

[12] R.W. Joyner, K. Kishi and M.W. Roberts, Proc. Roy. Soc. (London) A 358 (1977) 223.

[13] J.M. Eldridge and D.W. Dong, Surface Sci. 40 (1973) 512.

[14] M.P. Seah, Surface Sci. 32 (1972) 703.

[15] A.K. Green, S. Prigge and E. Bauer, Thin Solid Films 52 (1978) 163.

[16] M.G. Barthès and G.E. Rhead, Surface Sci. 85 (1979) L211.

[17] J. Perdereau, J.P. Biberian and G.E. Rhead, J. Phys. F (Metal Phys.) 4 (1974) 798.

[18] L.R. Pederson, J. Electron Spectrosc. Related Phenomena 28 (1982) 203.

[19] D.R. Penn, J. Electron Spectrosc. Related Phenomena 9 (1976) 29.

[20] H. Ohtani, C.T. Kao, M.A. Van Hove and G.A. Somorjai, Progr. Surface Sci. 23 (1986) 155. 